\title{
Gêneros digitais e relevância na construção de sentido: resultados interpretativos do chat em comparação com a conversação face a face
}

Digital text genres and relevance in meaning: chat interpretation results compared to face to face conversation

\author{
Dóris Cristina Gedrat*
}

\begin{abstract}
RESUMO: A partir das conclusões de pesquisas como Xavier (2002), Marcuschi (2010) e Araújo (2010) a respeito das qualidades do chat como gênero digital emergente, mostra-se, nesta pesquisa, como a interpretação relevante dos enunciados e, consequentemente, a construção de sentido durante a comunicação são influenciadas por tais propriedades, em comparação com o processo de compreensão durante uma conversação face a face. Sobre a interpretação dos sentidos, além do embasamento na teoria da relevância, de Sperber e Wilson (1986/1995), também se consideram as pesquisas em Yus (2008) quanto às alterações da relevância na web. Entre as principais conclusões está que os fatores intervenientes devido à transmutação da conversa cotidiana para a esfera da web tornam o processamento de efeitos contextuais e a avaliação da relevância, um processo altamente complexo, em que os participantes precisam ter habilidade para fazerem associações entre informações de diversos formatos com o fim de atingirem efeitos contextuais e relevância. Isso gera aumento do esforço mental e, consequentemente, diminuição das chances de se chegar à relevância ótima sugerida por Sperber e Wilson.
\end{abstract}

PALAVRAS-CHAVE: Construção de sentido. Relevância. Conversação face a face. Gêneros digitais. Chat.

\begin{abstract}
Considering Xavier's (2002), Marcuschi's (2010) and Araújo's (2010) conclusions on the peculiar qualities of a chat as an emergent digital text genre, this research aims at showing how relevant interpretation of utterances and, consequently, meaning apprehension during communication are influenced by chat's qualities when compared to the comprehension process during face to face conversation. Regarding sense interpretation, besides Sperber e Wilson's (986/1995), Yus's (2008) research on relevance alterations in the web is also considered. One of the main conclusions is related to the intervening factors in the process of face-to-face conversation transmutation to the web sphere. With the transmutation, contextual effects processing and, consequently, relevance evaluation become highly complex processes, in which participants must be able to make associations among information coming in many different formats in order to achieve contextual effects and relevance. This increases mental effort thus decreasing chances to reach the optimal relevant outcomes suggested by Sperber and Wilson.
\end{abstract}

KEYWORDS: Sense interpretation. Relevance. Face to face conversation. Digital text genres. Chat.

\footnotetext{
* Doutora em Linguística Aplicada (PUC/RS). Integrante do Curso de Letras da Universidade Luterana do Brasil (ULBRA), Canoas, RS.
} 


\section{Introdução}

No ambiente hipertextual da web, diferentes linguagens fundem-se, participando do processamento das informações na comunicação e, consequentemente, influenciando a maneira como os comunicadores realizam a construção de sentido relevante no contexto cognitivo. Este é o tema da pesquisa aqui apresentada.

Em primeiro lugar, exploram-se as principais noções sobre a comunicação enquanto processo cognitivo no qual informações novas interagem com o contexto de informações já presentes na memória dos participantes da comunicação, conforme a teoria da relevância, de Sperber e Wilson (1986/1995). Em seguida, a partir das conclusões de pesquisas como Xavier (2002), Marcuschi (2010) e Araújo (2010) a respeito das qualidades do chat como gênero digital emergente, descrevem-se as qualidades que o diferenciam da conversa face a face. Tais diferenças alteram, conforme proposto aqui, a maneira como os interlocutores recebem e processam os efeitos contextuais, influenciando, consequentemente, a avaliação da relevância de novas informações. Com respeito à interpretação relevante na web, considera-se a pesquisa de Yus (2008) sobre as alterações da relevância na cibermídia. Yus aponta as diferenças da disponibilidade de informação contextual em situações face a face e em encontros virtuais como causa dos diferentes resultados interpretativos ou da maior demanda de esforço mental para se chegar a efeitos interpretativos. ${ }^{1}$

Finalmente, confrontam-se as situações de conversa cotidiana com as situações de conversa online, o chat, através da análise de quatro fenômenos relacionados à relevância, explicados por Sperber e Wilson: a formação do contexto, a suposição de relevância ótima, a irrelevância de informações e as condições para relevância.

Mostra-se que a forma como os enunciados são transmitidos e recebidos no chat altera-se em relação à conversa face a face na medida em que ocorrem na esfera virtual, o que os leva a assimilar as qualidades dos gêneros dessa esfera, principalmente a natureza hipertextual da escrita em que se realiza, caracterizada pela bricolagem de semioses múltiplas, conforme Xavier (2002), fazendo com que os efeitos contextuais sejam disponibilizados e processados com a exigência de esforço extra para se atingir relevância.

\footnotetext{
${ }^{1}$ RAUEN (2010) está entre as pesquisas em Santa Catarina que também investigam as alterações da relevância no espaço da web, com aplicação ao ensino.
} 


\section{Cognição e construção de sentido relevante}

O pressuposto básico da teoria da relevância, de Sperber e Wilson (1986/1995), é o de que o comportamento humano, incluindo a comunicação, é dirigido, automaticamente e instintivamente, pela busca da relevância. A construção de sentido, segundo este pressuposto, depende da relevância dos enunciados. A informação mais relevante é aquela que produz o maior número de efeitos contextuais e exige o mínimo de esforço de processamento.

Nesse sentido, uma informação é relevante em um contexto no qual ela gera o maior número de efeitos contextuais e exige o menor esforço de processamento. Efeitos contextuais consistem na modificação e consequente aperfeiçoamento do contexto do enunciado, o que resulta no aperfeiçoamento da representação de mundo do ouvinte. O contexto, segundo Sperber e Wilson (1995, p.134), “consiste não apenas das suposições expressas ou implicadas por enunciados precedentes, mas também das entradas enciclopédicas ligadas a qualquer conceito usado nessas suposições”. Dessa forma, o contexto é um construto psicológico, um subconjunto das suposições do ouvinte sobre o mundo. São essas informações e suposições que afetam a interpretação dos enunciados, e não o estado real do mundo. ${ }^{2}$

A modificação do contexto ocorre através da interação entre informação nova e informação antiga, gerando efeitos contextuais. Estes podem ser de três tipos:

(1) Efeitos contextuais

(i) A informação nova combina-se com o contexto e produz implicações contextuais.

(ii) A informação nova combina-se com o contexto e reforça suposições já existentes no mesmo.

(iii) A informação nova combina-se com o contexto e contradiz suposições existentes, eliminando-as.

Nos três casos em que uma informação é relevante, pois produz efeitos contextuais, sempre há interação entre informação nova e informação antiga, nunca um efeito é produzido apenas por uma, ou por outra. E o contexto onde se processam as

\footnotetext{
${ }^{2}$ Compreendem-se, aqui os termos pensamento, informação e suposição conforme utilizados por Sperber e Wilson (1995, p. 2): “[...] com pensamentos queremos dizer representações conceituais (em oposição a representações sensoriais ou estados emocionais). Com suposições referimo-nos a pensamentos tratados pelo indivíduo como representações do mundo real (em oposição a ficções, desejos ou representações de representações). [...] Nós utilizaremos os termos de forma mais abrangente, tratando como informação não apenas fatos, mas também suposições dúbias ou falsas apresentadas como factuais”.
} 
informações pode ser formado a partir das informações armazenadas na memória enciclopédica, a partir de informações provindas do meio ambiente, as quais são captadas pelos sistemas sensoriais, ou a partir de representações da realidade implicadas pelo discurso precedente.

Por exemplo, considere-se o diálogo em (2):

(2) Filho (vestindo a camisa da Seleção Brasileira): Mãe, vou lá no Tiago ver futebol.

Mãe: A Copa terminou, agora tudo volta ao normal, lembra?

Ao interpretar o enunciado da mãe, suponhamos que o filho tenha um contexto, na memória de seu aparelho dedutivo, contendo as seguintes suposições:

(3) (a) A Copa terminou.

(b) A rotina de atividades do filho havia sido alterada devido à Copa.

(c) Entre as alterações estava a possibilidade de sair de casa em horário de realizar as tarefas escolares, para ver jogos da Copa.

(d) Com o final da Copa, o filho não pode mais sair de casa em horário previsto para realizar as tarefas escolares.

(e) A mãe quer que o filho fique em casa e estude.

A suposição (3a) é expressa no último enunciado a ser processado. As suposições (3b,c,d), combinadas a (3a), geram a implicação contextual (3e). Portanto, este é um exemplo de efeito contextual do tipo (i), em (1), em que a informação nova combina-se com o contexto e produz implicações contextuais.

O filho pode estender este contexto inicial, incluindo mais informações, como, por exemplo, as informações enciclopédicas sobre Tiago, em (4):

(4) (a) Tiago é um garoto que não dá muita atenção aos estudos.

(b) A mãe não gosta muito que o filho ande na companhia de Tiago.

A suposição contextual (4b) é reforçada com a informação nova, da mãe, em (2), gerando, assim, o efeito contextual (ii), mencionado em (1), quando a informação nova combina-se com o contexto e reforça suposições já existentes no mesmo.

Finalmente, pode-se exemplificar o terceiro tipo de efeito contextual, em (1), quando a informação nova combina-se com o contexto e contradiz suposições existentes, eliminando-as, ao considerarem-se outras suposições existentes do contexto do filho ao tentar sair de casa. Vejam-se (5a e b): 
(5) (a) Nas últimas três semanas, tenho ido muito à casa do Tiago.

(b) Vou jogar bola com o Tiago hoje.

A informação nova, isto é, o enunciado da mãe em (2), elimina a suposição contextual em (5b), gerando, assim, efeito contextual e, portanto, atingindo relevância neste contexto.

A comunicação, segundo Sperber e Wilson (1995, p. 158), é um ato ostensivo e intencional, por isso o estímulo produzido para que se inicie a comunicação é aprioristicamente relevante, e disso os autores depreendem a Suposição de Relevância Ótima e o Princípio de Relevância:

(6) Suposição de Relevância Ótima

a) O conjunto de suposições $\{\mathrm{I}\}$ que o comunicador pretende tornar manifesto ao ouvinte é relevante o suficiente para fazer valer a pena o ouvinte processar o estímulo ostensivo.

b) O estímulo ostensivo é o mais relevante que o comunicador poderia ter usado para comunicar $\{\mathrm{I}\}$.

(7) Princípio da Relevância

Todo ato de comunicação ostensiva comunica a presunção de sua relevância ótima.

Segundo esse princípio, as pessoas tentam encontrar o máximo de efeitos contextuais ao processarem informação e, ao realizar um ato de comunicação, cada comunicador sabe que o estímulo que ele escolheu é aquele que tem mais efeitos contextuais entre os que ele poderia ter escolhido. Alguns enunciados têm mais efeitos contextuais do que outros, por isso a força de sua relevância parece ser maior no contexto por eles acessado do que os outros em seus contextos.

Como a interação entre informação nova e contexto significa a informação nova produzir os efeitos contextuais descritos acima, uma informação nova processada é irrelevante nos seguintes casos: (1) a nova informação não tem conexão nenhuma com a informação já presente no contexto; (2) existe uma suposição equivalente no contexto, porém mais forte, de maneira que a nova suposição não afeta a força daquela que já existe, o que torna a nova informação não informativa e, portanto, irrelevante; (3) a nova suposição contradiz outras suposições existentes no contexto, mas não é forte o suficiente para eliminálas. $^{3}$

\footnotetext{
${ }^{3}$ Sperber e Wilson (1995, p.121) dizem, no entanto, que, mesmo nos casos em que a suposição propriamente dita é irrelevante, a escolha que o falante fez de utilizar uma suposição irrelevante pode ser relevante.
} 
Como foi explicado acima, a informação mais relevante é aquela que produz o maior número de efeitos contextuais pelo menor esforço de processamento mental. Dessa forma, o esforço de processamento exigido ao acessar-se o contexto para a interpretação do enunciado também afeta a avaliação dos graus de relevância, pois efeitos contextuais são produzidos por meio de processos mentais e estes, como todos os processos biológicos, exigem algum esforço. Para explicar a participação do efeito e do esforço na avaliação da relevância, Sperber e Wilson (1995, p.125) adotam o formato de definição com condições de extensão:

(8) Relevância

Condição de extensão 1: uma suposição é relevante num contexto à medida que seus efeitos contextuais neste contexto sejam grandes.

Condição de extensão 2: uma suposição é relevante num contexto à medida que o esforço exigido para processá-la neste contexto seja pequeno.

A partir dessa definição, pode-se verificar que a avaliação da relevância de um enunciado passa a ser uma questão de equilíbrio entre output e input, entre esforço de processamento e efeitos contextuais. De acordo com Sperber e Wilson (1995, p. 126-127), o esforço de processamento necessário para computar uma implicação contextual ou elevar ou baixar a força de uma suposição não é suficiente para anular a contribuição feita pela implicação à relevância. Por isso, o esforço para se computar uma implicação é proporcional aos efeitos por ele implementados, podendo ser ignorado.

Em resumo, segundo a teoria da relevância, a construção de sentido relevante ocorre mediante a interação entre informação nova e informação antiga. Ao interpretar um enunciado, logo, ao tentar ir ao encontro da intenção comunicativa do falante, o ouvinte entra num processo de interpretação que envolve acesso a conceitos e entradas enciclopédicas (formação de hipóteses) e dedução (confirmação ou rejeição de hipóteses). Assim, a interpretação de um enunciado será o processamento de informações novas combinadas a informações antigas. As informações antigas estão na memória em forma de conceitos aos quais se ligam informações enciclopédicas. As informações nos conceitos e na enciclopédia formam o contexto no qual o enunciado é processado. Portanto, durante o processamento de um enunciado, o contexto vai se formando, a partir de um contexto inicial, e se modificando com o reforço e a eliminação de suposições e com o aparecimento de novas suposições contextuais, que são as implicaturas (suposições e conclusões implicadas). 
Tendo sido apresentadas as noções principais sobre a comunicação como processo cognitivo no qual informações novas interagem com o contexto de informações já presentes na memória dos participantes da comunicação, passa-se, na seção 3, a descrever o chat enquanto gênero na web e as qualidades que o diferenciam da conversa face a face. Tais diferenças alteram, conforme proposto aqui, a maneira como os interlocutores recebem e processam os efeitos contextuais, influenciando, consequentemente, a avaliação da relevância de novas informações.

\title{
3. O chat entre os gêneros digitais emergentes
}

Segundo Marcuschi (2010, p.15), “há um conjunto de gêneros textuais que estão emergindo no contexto da tecnologia digital em ambientes virtuais”. Ele afirma:

\begin{abstract}
Os gêneros emergentes nessa nova tecnologia são relativamente variados, mas a maioria deles tem similares em outros ambientes, tanto na oralidade como na escrita. Contudo, sequer se consolidaram, esses gêneros eletrônicos já provocam polêmicas quanto à natureza e proporção de seu impacto na linguagem e na vida social. Isso porque os ambientes virtuais são extremamente versáteis e hoje competem, em importância, entre as atividades comunicativas, ao lado do papel e do som. Em certo sentido, pode-se dizer que, na atual sociedade da informação, a Internet é uma espécie de protótipo de novas formas de comportamento comunicativo (MARCUSCHI, 2010, p.15-16).
\end{abstract}

Antes de definir cada gênero digital emergente, Marcuschi (2010, p.31) esclarece que o gênero não se confunde com os ambientes gerados pela tecnologia. Os ambientes, ou entornos virtuais, abrigam os gêneros e, por vezes, os condicionam. Assim, seguindo Wallace (2001), o autor descreve um dos ambientes virtuais existentes, o chat síncrono: “ambientes em salas de bate-papos entre várias pessoas simultaneamente ou em ambiente reservado. Tem vários formatos no estilo de uma conversação em tempo real. Também vem sendo usado para aula-chat”. Segundo Marcuschi, esses ambientes são locais onde os gêneros aparecem, permitindo “culturas” variadas, e sua classificação em tipologias auxilia a compreender tais culturas.

O gênero que nos interessa aqui é um dos que se realiza no ambiente acima descrito, e suas variantes, o chat em aberto (bate-papo virtual em aberto - room-chat), em que inúmeras pessoas interagem simultaneamente em relação síncrona e no mesmo ambiente. As variantes são: o chat reservado (bate-papo virtual reservado), com as falas pessoais acessíveis apenas a dois interlocutores mutuamente selecionados, embora com 
acesso aos demais em aberto; chat agendado (bate-papo agendado - ICQ), como o reservado, mas tendo sido agendado, oferecendo a possibilidade de mais recursos tecnológicos na recepção e envio de arquivos; chat privado (bate-papo virtual em salas privadas), em que apenas dois parceiros de diálogo estão presentes.

Para Marcuschi, é importante investigar a real novidade das práticas, como, por exemplo, nos bate-papos abertos, em que, segundo o autor (p.35), "são construídas identidades sociais muito diversas daquelas das conversações face a face”. Uma característica marcante em todos esses gêneros digitais emergentes é a utilização da escrita, divergência em relação a suas contrapartes preexistentes ${ }^{4}$.

Segundo Araújo (2004, p. 91), o chat é o resultado da transmutação de um gênero existente para um gênero na web: “[...] a conversação em tempo real, ocorrida nos chats, é resultado da transmutação do diálogo cotidiano de sua esfera de origem para uma esfera eletrônica, que é a Web”. O autor explica, em Araújo (2010, p.111), “que é possível flagrar as marcas da transmutação sofrida pelo chat, a partir da bricolagem das semioses somimagem-escrita que se materializa em sua estrutura composicional.”

Araújo toma como base a teoria de Bakhtin (1997) para embasar sua tese de que o chat constitui um novo gênero. Bakhtin (1997, p.279-281) mostra que a comunicação realiza-se em esferas, as quais são formadas por "repertórios de gêneros”. Os gêneros organizam as práticas discursivas no interior das esferas. Segundo o mesmo autor, dependendo das esferas, os gêneros são primários ou secundários. Os gêneros primários surgem das “circunstâncias de uma comunicação verbal espontânea” e os secundários são próprios de "uma comunicação cultural mais complexa e [...] evoluída, principalmente escrita”. Entre os gêneros primários Bakhtin inclui o diálogo cotidiano e a carta e, entre os secundários estão o romance e o discurso científico.

Em Araújo (2010, p. 114), o autor esclarece que assim como as esferas tornam-se mais complexas, os gêneros também se modificam e reformatam, "para dar conta das novas necessidades instauradas nas esferas, que também tendem a se hibridizar, sendo este o caso da web”. Segundo Bakhtin, existe transmutação quando um gênero primário dá origem a um novo gênero secundário, transmutando-se de uma esfera para outra, originando novos gêneros que apresentam um estilo similar ao domínio discursivo que o absorveu. Nesse sentido, para Araújo (2010, p. 115):

\footnotetext{
${ }^{4}$ No caso dos gêneros chat, as contrapartes preexistentes propostas por Marcuschi (2010, p.37) como tentativas aproximadas são, respectivamente, as conversações (em grupos abertos?), as conversações duais (casuais), os encontros pessoais (agendados?) e as conversações (fechadas?).
} 
[...] o chat é oriundo do que Bakhtin chama de diálogo cotidiano, uma vez que as marcas da conversa cotidiana permanecem no chat. No entanto, tais marcas, uma vez transmutadas pela web, parecem gerar uma nova formatação do diálogo cotidiano, o que permitiu a formulação da hipótese segundo a qual o chat é uma situação comunicativa complexa pela qual se chega a vários gêneros emergentes.

Na figura 1, Araújo (2010, p.117) propõe sua adaptação das noções de esfera complexa de comunicação e transmutação de Bakhtin (1997), para dar conta da sua proposta de que o chat configura-se como um gênero emergente na web:

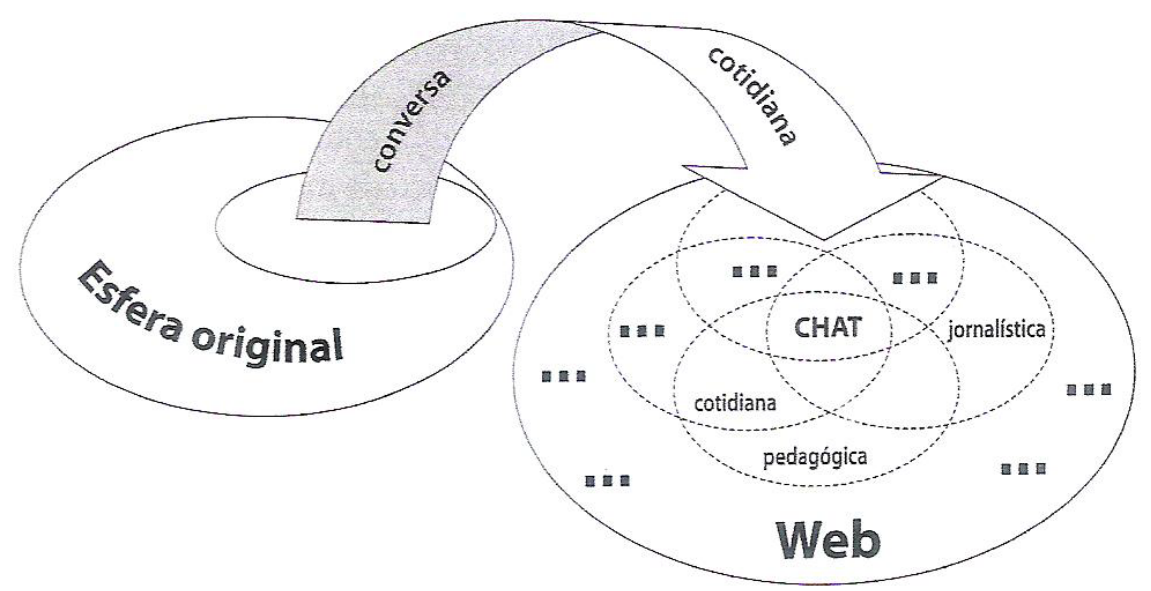

Figura 1: Transmutação do diálogo cotidiano para a web Fonte: Araújo (2010, p.117)

Segundo a proposta de Araújo, a web não seria uma esfera de comunicação geradora de discursos através da qual se chega aos gêneros, tal qual proposto por Bakhtin. "Na verdade, estamos diante de um espaço plural no qual não apenas muitos gêneros são atualizados, mas diversas esferas de comunicação também” (ARAÚJO, 2010, p. 118). Como se pode ver na figura 1 , a palavra chat encontra-se na intersecção de algumas esferas, mostrando que ele pode servir aos interesses de vários domínios discursivos transmutados pela web, "como o cotidiano que se serve de chats abertos ou chats reservados; o domínio discursivo pedagógico que pode fazer uso do gênero chat educacional e o domínio discursivo jornalístico que tem feito uso de chat com convidado". (ARAÚJO, 2010, p. 118)

Como o chat e todos os outros gêneros emergentes da web trazem as marcas deste espaço plural de práticas de linguagens, Araújo destaca que, entre estas marcas, está a hipertextualidade, que também integra a constituição do chat. Na figura 1, a seta que liga os dois círculos grandes, indicando a transmutação do diálogo cotidiano de sua esfera de 
origem para a web, representa a hipertextualidade constitutiva do chat. ”Verifica-se, ainda, que a seta não só conduz o diálogo cotidiano para o chat, mas representa a assimilação daquele no interior deste, reinterpretando-o.” (ARAÚJO, 2010, p. 118)

A noção de hipertexto adotada por Araújo considera a não-linearidade da/na hiperleitura e os links e nós textuais, mas não limita-se a isso, considerando, também, conforme Xavier (2002), a reunião das várias mídias. Araújo (2010, p. 132) esclarece, a respeito da figura 1:

[...] além do som, [...], a imagem representa para o chat um outro recurso de hipertextualidade, cuja função é a de transmutar gestos e atitudes, peculiares a um diálogo convencional, para a riqueza plurissemiótica do chat na Web. Esta constatação pode ser relacionada com a complexa formação de gêneros sugerida por Bakhtin (1997, p.281), uma vez que a imagem, transposta para o chat, "perde relação imediata com [sua] realidade anterior”, já que se torna componente desse novo gênero.

No ambiente hipertextual da web, diferentes linguagens fundem-se, participando do processamento das informações na comunicação e, consequentemente, influenciando a maneira como os comunicadores realizam a construção de sentido relevante no contexto cognitivo. Este será o tema da próxima seção.

\section{Contexto de interpretação relevante no chat e na conversação face a face}

A conversa cotidiana, "transmutada”, nos termos de Araújo (2010), para o chat teria a interpretação das informações, logo a construção de sentido do texto, alterada por estar numa esfera hipertextual? Essa é a pergunta norteadora nesta pesquisa. Poder-se-ia dizer que essa transmutação, que altera o estilo da escrita, alteraria também a relevância das informações?

Para chegar às análises e conclusões a seguir, partiu-se da premissa exposta no início do artigo, a saber: "No ambiente hipertextual da web, diferentes linguagens fundem-se, participando do processamento das informações na comunicação e, consequentemente, influenciando a maneira como os comunicadores realizam a construção de sentido relevante no contexto cognitivo”.

Seguindo o princípio da relevância de Sperber e Wilson (1986/1995) - com ênfase no caráter cognitivo da comunicação, em que novas informações interagem com informações já presentes na memória do indivíduo -, tomando por base as descrições e 
dados trazidos por Xavier (2002), Marcuschi (2010) e Araújo (2010) sobre a diferença entre a conversa cotidiana e o chat hipertextual, além de considerar as descobertas de Yus (2008) sobre o comportamento diferenciado da relevância em textos regulares e em textos na cibermídia, foram selecionados quatro fenômenos explicados por Sperber e Wilson, centrais à teoria da relevância e, portanto, ao processamento de informação e à interpretação do sentido durante a comunicação humana. Esses fenômenos foram analisados à luz das diferenças entre a conversa cotidiana e o chat, a fim de se visualizar como a relevância é alterada e, consequentemente, os significados são interpretados de maneira diferenciada na comunicação via cibermídia. Tais fenômenos são a formação do contexto, a suposição de relevância ótima, a irrelevância de informações e as condições para relevância.

A seguir, retomam-se as principais características do chat e a maneira como elas o tornam diferente da conversa face a face, para, então, proceder à análise dos quatro fenômenos ligados à relevância de enunciados, na tentativa de mostrar como os resultados interpretativos do chat, no que tange à relevância e à interpretação de sentidos, são encaminhados de forma diferente se comparados aos da conversa cotidiana.

\subsection{Características do chat enquanto gênero transmutado}

Retomando o que foi demonstrado, o chat é considerado por alguns estudiosos um gênero hipertextual. Araújo (2010, p.125), nesse sentido, afirma:

[...] os chats que acontecem na web poderiam ser chamados de chats hipertextuais, por trazerem, em sua textura, marcas indeléveis da riqueza plural da linguagem do hipertexto, de modo que os elementos sonoros, imagéticos e escritos se fundem para compor o texto conversacional, ainda que a escrita, nestes gêneros, apresente características distintas da usual. Isso acontece porque a web é um serviço da internet baseado no hipertexto e, por isso, seus gêneros se atualizam com marcas hipertextuais. Sendo assim, a natureza dos chats na web muda, consideravelmente, porque eles trazem as marcas hipertextuais da hiperesfera em que se atualizam.

Ao descrever as marcas da transmutação da conversa para o chat hipertextual, Araújo (2010) destaca alguns exemplos contendo som e imagem, fundindo-se com a escrita e alterando o formato desta no chat. Na figura 2, as palavras sublinhadas vêm acompanhadas de som, chamando a atenção do interlocutor, que pode estar em atividade paralela na internet, como enviando e-mails, ou outra: 


\section{(12:48:26) Secretå videokê @ grita com b@nb@n@: perdaum, estava minimi-} zada vendo o e-mail! Mas ouvi teu chamado e vim :-))

Figura 2. Referência ao som na escrita do chat. Fonte: Araújo (2010, p.126)

Na figura 2, segundo Araújo, o recurso do som não faz parte da composição do texto conversacional, embora seja importante por estabelecer interação entre os interlocutores. Na figura 3, o autor mostra uma ocorrência em que o som faz parte da composição do texto, apresentando materialidade acústica e visual:

\section{(15:18:41) NokululeOon@h@h grita com TODOS:ATENÇAUM TANANANS TIVAR MIDIS!!!!!! \\ (15:19:34) NokululeOon@h@h grita TODOS: CLIKEM LÁ EM CIMA EM "PERMITIR MIDI" \\ (15:21:35) MEL $(*)$ LULA LÁ grita com NokululeOon@h@h: kd o midi? \\ (15:21:47) NokululeOon@h@h grita com MEL $(\div)$ LULA LÁ: perai \\ (15: 25:01) NokululeOon@h@h grita com TODOS: I \\ (15:29:16) åi @ömu tö nervoso grita com NokululeOon@h@h este som é manero. Valeu, amigaum de qual site??? \\ (15:55:03) NokululeOon@h@h grita com ăi @ömu tö nervoso: entra no www. geocities.com/audiostore99}

Figura 3. Materialidade acústica e visual na comunicação via chat.

Fonte: Araújo (2010, p.127)

Como se pode notar, na sétima linha há um ícone, uma marca visual da manifestação sonora. Além disso, a escrita em maiúsculas marca visualmente o tópico da conversação. As três linguagens - o som, a imagem e o texto -, coexistem harmonicamente no hipertexto. Xavier (2002, p. 100) discorre a respeito da união dos vários modos de enunciar no hipertexto:

Essa bricolagem digital de modos de enunciação, em uma mesma e única tecnologia enunciativa, apoia [a] teoria de que o hipertexto disponibiliza ao homem pós-moderno mais um modo de enunciar: o digital, e, ao mesmo tempo, descentraliza a escrita, enquanto tecnologia enunciativa dominante. O hipertexto pulveriza os modos de enunciação e esvazia não só a ideia de predomínio do modo verbal, mas lança [...] vários outros modos que devem ser processados 'todos ao mesmo tempo agora'. 
Com base nos dados em Marcuschi (2010), Araújo (2010) e Xavier (2002), mostra-se, na sequência, como a interpretação relevante dos enunciados e, consequentemente, a construção de sentido durante a comunicação são influenciadas pelas propriedades do gênero digital emergente aqui enfocado, o chat, em comparação com o processo de compreensão durante uma conversação face a face. Sobre a interpretação dos sentidos, além do embasamento na teoria da relevância, de Sperber e Wilson (986/1995), também se consideram as pesquisas em Yus (2008) quanto às alterações da relevância na web.

\subsection{Resultados interpretativos do chat em comparação com a conversação face a face}

O chat, conforme descrito e analisado nas seções anteriores, identifica-se como um gênero digital cujas qualidades o diferenciam amplamente da sua contrapartida face a face: (1) o diálogo cotidiano é marcado pela oralidade enquanto o chat caracteriza-se por uma linguagem oriunda da bricolagem de várias mídias (texto, som, imagem); (2) a reunião de várias mídias, os nós e os links textuais transformam o chat num gênero hipertextual, esvaziando, segundo Xavier (2002, p.100), a ideia de predomínio do modo verbal e lançando vários outros modos que devem ser processados "todos ao mesmo tempo agora”.

Tais características diferenciadoras do chat com relação à conversa cotidiana levam pesquisadores como Yus (2008), entre outros, a investigarem o comportamento da relevância, comparando o chat com a sua contrapartida face a face:

[...] algumas qualidades da cibermídia [...] podem alterar a avaliação da relevância (a combinação entre efeitos cognitivos e esforço mental [...]) na informação vinda da troca entre essas mídias e podem influenciar no resultado bem/mal sucedido da comunicação na web. [...] a falta de qualidades orais que as conversações mediadas pela internet exibem podem gerar esforço de processamento adicional quando se procura por uma interpretação relevante (efeitos similares são obtidos, mas o usuário precisa se esforçar mais para retê-los na comunicação baseada no texto). [...] o destinatário precisa dispender esforço mental suplementar para obter algum efeito cognitivo que seria mais fácil reter em situações mais contextualizadas (i.e., com mais suporte de informação não verbal de origem oral e visual). [...] na comunicação baseada em texto da internet, há mais lacunas a serem preenchidas inferencialmente, gerando mais esforço mental devotado para obter efeitos cognitivos semelhantes. (YUS, 2008, p. 634-635) 
A pesquisa aqui apresentada tem como objetivo apontar de que modo a interpretação do sentido, segundo a teoria da relevância de Sperber e Wilson (1986/1995), é influenciada pelas qualidades do gênero digital chat em comparação com a interpretação realizada pelos participantes da conversação face a face. A partir das conclusões de pesquisas como Xavier (2002), Marcuschi (2010) e Araújo (2010) a respeito das qualidades desse gênero digital emergente, analisam-se, a seguir, quatro fenômenos relacionados à relevância, explicados por Sperber e Wilson: a formação do contexto, a suposição de relevância ótima, a irrelevância de informações e as condições para relevância. Não há, aqui, a intenção de, a exemplo de Yus (2008), reescrever as condições para relevância de enunciados a partir da nova situação da conversa realizada na web, mas sim a de colaborar com as pesquisas na área da semântica e da pragmática e sua aplicação às diversas práticas sociais que envolvem a interpretação no uso da linguagem e a construção do sentido em situações de comunicação.

\subsubsection{Formação do contexto de comunicação: a origem das suposições que o compõem}

Conforme apresentado na primeira parte deste trabalho, segundo Sperber e Wilson (1995, p.134), os efeitos contextuais são produzidos mediante a interação entre informação nova e informação antiga, esta já presente no contexto de comunicação. As informações do contexto são aquelas armazenadas na memória enciclopédica, aquelas que provêm do meio ambiente, aquelas captadas pelos sistemas sensoriais e aquelas formadas a partir de representações da realidade implicadas pelo discurso precedente.

Embora, no caso do chat, possa-se considerar que o contexto seja formado dessa mesma maneira, também se devem considerar, conforme demonstram as pesquisas aqui mencionadas - Araújo (2010), Marcuschi (2010) e Xavier (2002) -, as qualidades diferenciadoras do chat enquanto gênero emergente na web, as quais afetam a origem das suposições e informações que compõem o contexto, afetando, portanto, o comportamento da relevância nos ambientes virtuais. A escrita, modalidade da língua em que o chat se concretiza, é entremeada por outras linguagens, como a imagem e o som, sem, no entanto, fazer-se uso de gestos, expressões faciais e entonação, próprias da oralidade face a face. Isso altera o formato das informações contextuais provindas do meio ambiente, aquelas captadas pelos sistemas sensoriais e aquelas formadas a partir de representações da realidade implicadas pelo discurso precedente, conforme dito no parágrafo anterior, uma 
vez que tanto o meio ambiente quanto o discurso precedente integram, em grande parte, o meio digital. Em grande parte porque, mesmo estando neste ambiente, o meio ambiente físico está presente na realidade de cada um que digita, fazendo, portanto, sua parte na composição do contexto.

Assim, com base na figura 2, reproduzida em (9), pode-se visualizar em parte a alteração no formato das informações provindas do meio ambiente, uma das fontes para a formação do contexto comunicativo segundo a teoria da relevância:

(9) Figura 2

(12:48:26) Secretå videokê @ grita comb@nb@n@: perdaum, estava minimizada vendo o e-mail! Mas ouvi teu chamado e vim :-))

Nesta fala de chat, a internauta Secretẳ videokê ${ }^{\circledR}$ utiliza sinais de diversas linguagens em sua escrita, caracterizando a bricolagem hipertextual do gênero. A oralidade está presente na escrita de “perdaum”, imitando, na grafia, o som dos fonemas produzidos na fala; o sublinhado representa visualmente o som da alteração no tom da voz; os termos "minimizada”, “ouvi” e "vim” transportam a falante para dentro da esfera onde se dá a troca, para dentro da web.

A transmutação de uma esfera para outra fica clara a partir desses destaques, permitindo que se visualize o diferente formato das informações contextuais. A oralidade, conforme representada na escrita neste turno de fala, transforma tanto uma, quanto outra modalidade: alterando a escrita (“perdaum” ao invés de "perdão”), introduzindo sinais extralinguísticos como parte dessa escrita (sublinhado com significado de aumento no tom da voz). Além disso, as informações sensoriais também sofrem alteração, uma vez que a internauta se diz "minimizada”, colocando-se no lugar de uma tela do computador, além de dizer que “ouviu” o chamado (o sinal sonoro produzido para alertar alguém sobre algo que está acontecendo, como, por exemplo, um chamado para conversar) e "vim”, como se tivesse se deslocado para outro ponto da web, o que explicita a característica hipertextual do chat.

Os participantes do discurso estão no ambiente físico, mas não no mesmo, e eles compartilham um ambiente virtual, mas cada um também recebe as informações sensoriais provindas do ambiente físico onde se encontram. Pode-se dizer que esse e os demais efeitos da transmutação apontados acima alteram tanto a forma como o falante emite seus estímulos e sua escolha pelo enunciado mais relevante, quanto o recebimento, 
por parte do ouvinte, dos estímulos enviados e do esforço de processamento para atingir efeitos contextuais e, portanto, relevância.

\subsubsection{A suposição de relevância ótima dos enunciados}

Por suposição de relevância ótima, Sperber e Wilson (1995, p. 158) entendem que o estímulo escolhido pelo comunicador é o mais relevante que ele poderia ter escolhido no momento e, portanto, merece o esforço de processado por parte de seu interlocutor. No caso da comunicação nos meios digitais, não há por que pensar que isso não ocorra, embora, novamente, o processo seja alterado pelas qualidades diferenciadoras que definem o chat. Como se pode ver na figura 1, que ilustra a transmutação da conversa cotidiana para o chat hipertextual, o gênero de origem não apenas é transportado para o chat, mas assimilado no interior dele, havendo, nesta transmutação, segundo Araújo (2010, p. 132), a transformação de "gestos e atitudes, peculiares a um diálogo convencional, para a riqueza plurissemiótica do chat na Web".

A riqueza plurissemiótica a que Araújo se refere diz respeito à bricolagem somimagem-texto, características da esfera hipertextual, novamente alterando a formatação do texto escrito, agora permeado de oralidade. Assim, o estímulo produzido/recebido durante a comunicação, mesmo sendo o mais relevante possível para os propósitos comunicativos, será produzido/recebido por vias diversas daquelas em que isso ocorre no diálogo face a face. Como a acessibilidade das informações contextuais é alterada, assim também os efeitos contextuais podem ser diferentes.

Novamente considerando a figura 2, vê-se que o estímulo escolhido como sendo o mais relevante não seria o mesmo que seria escolhido numa situação de diálogo face a face. Nesta, todas as marcas da oralidade que estão inseridas na escrita de Secretẳ videokêe ${ }^{\circledR}$ estariam sendo emitidas com gestos, com alteração do tom de voz e expressões faciais. O deslocamento da falante para outra esfera também não ocorreria, pois os dois participantes do diálogo estariam, um em frente ao outro, ou pelo menos no mesmo ambiente físico, sem precisar criar mecanismos para referir à sua presença ou à do outro.

Vê-se, com isso, novamente, a alteração na forma como as suposições contextuais são emitidas e recebidas, para que os efeitos sejam computados e a relevância atingida em situações de trocas verbais na comunicação digital. Por outro lado, com as escolhas diferenciadas em função das características ambientais e do contexto que mistura o físico com o virtual, observa-se que a procura pelo estímulo mais relevante é preservado, 
conforme defendido por Sperber e Wilson (1995), na teoria da relevância. Ou seja, dentro do ambiente em que se encontram, conforme as qualidades do meio físico e, no caso do chat, virtual/hipertextual no qual atuam, os participantes do discurso sempre escolhem os estímulos mais relevantes, isto é, aqueles que geram o maior número de efeitos contextuais pelo menor esforço de processamento possível.

\subsubsection{A irrelevância de novas informações}

Uma informação é irrelevante, segundo Sperber e Wilson (1995, p. 121), quando não possui conexão com nenhuma suposição presente no contexto, ou quando já existe uma suposição equivalente, porém mais forte, no contexto, a qual não é afetada pela nova suposição, ou ainda quando a nova suposição contradiz outras já existentes no contexto, mas não é forte o suficiente para eliminá-las.

Para exemplificar, considere-se a figura 3, reproduzida em (10):

\section{(10)Figura 3}

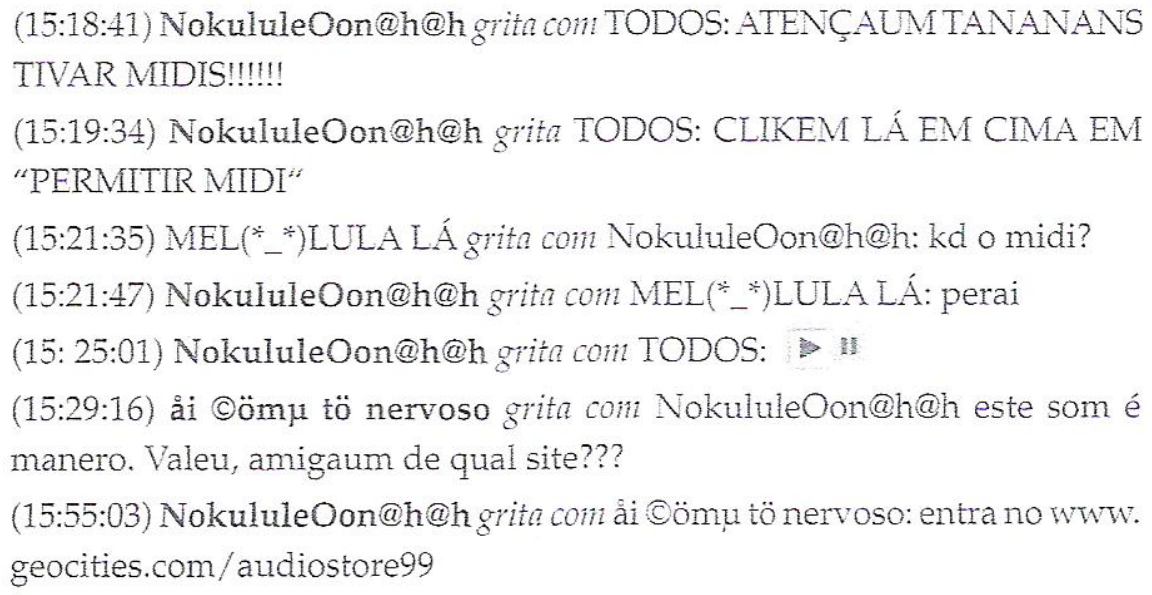

Tomando como contexto as suposições na mente de ái @õm $\mu$ to nervoso e de NokululeOon@h@h, no diálogo acima, qualquer uma das novas informações em (11), se proferidas pelo internauta ái @õm $\mu$ to nervoso, após a fala de NokululeOon@h@h, seriam irrelevantes:

(11)a. Antes da construção de Brasília, o Rio de Janeiro era a capital do país.

b. Isto é um chat de conversa.

c. Você está dormindo. 
A informação (11a) é irrelevante por ser completamente arbitrária no contexto, não produzindo efeitos contextuais, não tendo conexão com as suposições contextuais existentes. A irrelevância de (11b) se dá porque os interlocutores já estão cientes quanto ao chat, de modo que qualquer implicação desse enunciado existe no contexto, já tendo, portanto, sido computada. Quanto à (11c), trata-se de uma suposição inconsistente no contexto, por isso irrelevante. O interlocutor está ciente não apenas de estar conversando num chat, mas também de que essa atividade é incompatível com estar dormindo, tratando-se, portanto, de uma contradição. Como a nova informação não consegue excluir a que já existe, ela não causa nenhum efeito contextual, sendo, então, irrelevante.

Portanto, com relação à irrelevância de novas suposições e informações, nas trocas do chat, uma nova informação é irrelevante pelos mesmos motivos arrolados por Sperber e Wilson (1995), quando falam da comunicação face a face: a nova informação não possui conexão com nenhuma suposição presente no contexto, ou já existe uma suposição equivalente a ela, porém mais forte, por isso não é afetada pela nova suposição, ou ainda, a nova suposição contradiz outras já existentes no contexto, mas não é forte o suficiente para eliminá-las. Essas três fontes de irrelevância de uma nova informação/suposição foram exemplificadas acima, considerando o chat. Além disso, também se pode ver que, conforme dito por Sperber e Wilson (1995, p. 121), a escolha por um enunciado irrelevante pode ser altamente relevante no estágio em que se encontra a comunicação, segundo os propósitos do falante. Ou seja, a escolha de (11a), (11b) ou (11c) por ái @õm $\mu$ to nervoso pode ser proposital, com vistas a atingir a relevância que deseja que seu interlocutorNokululeOon@h@h atinja. Por exemplo,ái @õm $\mu$ to nervoso poderia estar querendo disfarçar e mudar de assunto, pois sabe que algum outro internauta conhecido está conectado e não quer que ele saiba da conversa que está tendo com NokululeOon@h@h.

Por outro lado, novamente, a forma como os enunciados irrelevantes são transmitidos e recebidos altera-se em relação à conversa face a face na medida em que ocorrem na esfera virtual, o que os leva a assimilar as qualidades do gênero chat, principalmente a natureza hipertextual da escrita em que se realiza, caracterizada pela bricolagem de semioses múltiplas, conforme Xavier (2002). Essa variação em relação à conversa face a face leva o chat à utilização de sinais e marcas que não pertencem à escrita comum, mas que são utilizados em grande parte para compensar a falta dos gestos e das expressões faciais, além do tom de voz, fazendo com que os efeitos contextuais sejam 
disponibilizados e processados com a exigência de esforço extra para se atingir relevância.

\subsubsection{Condições para relevância}

As condições para que um estímulo seja relevante estão expressas em (8) e são reproduzidas a seguir:

(8) Relevância

Condição de extensão 1: uma suposição é relevante num contexto à medida que seus efeitos contextuais neste contexto sejam grandes.

Condição de extensão 2: uma suposição é relevante num contexto à medida que o esforço exigido para processá-la neste contexto seja pequeno.

Como o processamento de informações é um processo mental, ele exige esforço, o qual entra na avaliação da relevância. Se uma informação produz efeitos contextuais exigindo demasiado esforço mental, outra que produza os mesmos efeitos e exija menos esforço de processamento atingirá um grau mais alto de relevância do que ela.

Conforme Yus (2008, p. 637):

Leitores de cibernotícias também acessam a relevância da informação que estão lendo, mas a forma como o texto é apresentado e a disponibilidade das informações contextuais em ambas as mídias (impressa e online) pode alterar o equilíbrio entre efeitos cognitivos e esforço de processamento, consequentemente, da eventual satisfação do usuário.

Yus chega a propor que as condições para relevância sejam reescritas quando se referem a textos adaptados para a internet. Ele considera, entre outros, o fato de que a relevância do que um leitor recebe online tem origem na combinação de fontes diferentes de informação, não na leitura linear de um artigo de notícia. Assim, Yus (2008, p. 638) propõe a seguinte alteração nas condições de relevância propostas por Sperber e Wilson:

Condição (a): Uma suposição é relevante para um indivíduo à medida que os efeitos contextuais atingidos quando ela é otimamente processada sejam grandes.

Condição (b): Uma suposição é relevante para um indivíduo à medida que o esforço exigido para processá-lo otimamente não seja inutilmente aumentado pela qualidade da interface (ou por que o texto processado tenha sido literalmente transferido para a mídia online, ou por que as fontes adicionais de informação contextual não oferecem interesse suplementar em troca deste esforço). 
O autor refere-se a textos na internet de forma geral, mas, considerando as trocas comunicativas no chat, também é possível apontarem-se características desse gênero que podem bem interferir no recebimento da informação e no seu processamento, afetando a relevância. Conforme Araújo (2010, p. 115), já citado anteriormente, “as marcas da conversa cotidiana permanecem no chat”, mas, “uma vez transmutadas pela web, parecem gerar uma nova formatação do diálogo cotidiano”.

Araújo (2010, p. 132), também já citado anteriormente, explica que, além do som, “a imagem representa para o chat um outro recurso de hipertextualidade, cuja função é a de transmutar gestos e atitudes, peculiares a um diálogo convencional, para a riqueza plurissemiótica do chat na Web.” Todas essas características diferenciadoras do chat em relação à conversa cotidiana, face a face, fazem com que a disponibilização e o processamento de efeitos contextuais durante a comunicação sejam um tanto mais complexos no meio digital, uma vez que, além de não contarem com o apoio de fatores extralinguísticos próprios da comunicação cotidiana, também “misturam” diversas linguagens numa escrita completamente modificada em relação à escrita comum.

Observe-se, novamente, a figura 3, reproduzida em (12), como exemplo do ponto aqui tratado, de que as condições para relevância são alteradas no chat, se comparadas à conversa cotidiana. Imagine-se a conversa no chat da figura 3 realizada face a face, conforme (13), onde os nomes dos internautas foram substituídos por letras (A,B, C):

\section{(12)Figura 3}

(15:18:41) NokululeOon@h@h grita com TODOS:ATENÇAUMTANANANS TIVAR MIDIS!!!!!!

(15:19:34) NokululeOon@h@h grita TODOS: CLIKEM LÁ EM CIMA EM "PERMITIR MIDI"

(15:21:35) MEL(*) LULA LÁ grita com NokululeOon@h@h: kd o midi?

(15:21:47) NokululeOon@h@h grita com MEL $\left(_{-}^{*}\right)$ LULA LÁ: perai

(15: 25:01) NokululeOon@h@h grita com TODOS: D u

(15:29:16) åi @ömu tö nervoso grita com NokululeOon@h@h este som é manero. Valeu, amigaum de qual site???

(15:55:03) NokululeOon@h@h grita com åi@ömu tö nervoso: entra no www. geocities.com/audiostore99

(13)A: Todos! Atenção! Ativar as mídias! Todos cliquem em cima de "Permitir mídias"!

B: Cadê as mídias, A?

A: Espera. Todos cliquem no ícone com a seta e o sinal de pausa.

C: Esse som é manero, A. Valeu, amigão, de qual site? 
A: Entra no www:geocities.com/audiostore99.

Em primeiro lugar, a versão face a face em (13), do diálogo no chat em (12), integra todos os participantes no mesmo ambiente físico, que é uma das fontes de informações contextuais para a interpretação de novas informações e suposições. Sabemos que, no ambiente cognitivo de cada indivíduo, o mesmo estímulo físico e a mesma informação percebida pode associar-se de forma diferente às informações contextuais já existentes. Mesmo assim, o fato de o ambiente físico ser o mesmo para todos é uma boa indicação de que os mesmos fatores contextuais estarão disponíveis de forma igual a todos, o que os torna mais facilmente processáveis por todos também, tornando as condições para relevância mais fáceis de serem atingidas.

Além disso, vê-se, em (12), a transmutação de sons, de gestos e atitudes próprios da conversa convencional para a riqueza plurissemiótica do chat na Web, mencionada por Araújo (2010, p. 132). Tais alterações também levam a alterações na disponibilidade e na forma como são processados os efeitos contextuais durante a comunicação. Todos os efeitos gerados pelas diferentes linguagens (som, imagem, escrita) estão representados ao mesmo tempo no texto do chat, tendo sido transmutados do ambiente convencional de uma conversa. Tal carga de efeitos de naturezas diversas de uma só vez também influencia a forma como cada um é processado e, portanto, a sua força na modificação do ambiente cognitivo durante a comunicação.

Nesse sentido, Yus (2008) propõe a reescrita das condições para relevância acima citada. Os fatores intervenientes devido à transmutação da conversa cotidiana para a esfera da web tornam o processamento de efeitos contextuais, logo, a avaliação da relevância, um processo altamente complexo, em que os participantes precisam ter habilidade para fazerem associações entre informações de diversos formatos para atingirem efeitos contextuais e relevância. Isso gera aumento do esforço mental e, consequentemente, maiores chances de não se chegar à relevância ótima sugerida por Sperber e Wilson.

\section{Considerações finais}

Com esta pesquisa, almejou-se trazer à tona as transformações que um gênero textual sofre ao ser transmutado para a esfera da web, tendo como foco principal os efeitos dessas transformações na avaliação da relevância e na construção do sentido do texto. O texto escolhido foi o chat, oriundo, segundo Bakhtin (1997), do diálogo cotidiano. 
Verificou-se que, ao ser transmutado, o diálogo cotidiano perde algumas de suas características marcantes, como, por exemplo, concretizar-se, predominantemente, na oralidade, e assimila características dos gêneros digitais, como, por exemplo, a natureza hipertextual, incluindo a bricolagem de várias semioses (som-imagem-texto). Tudo isso altera o processamento das informações e a forma como são disponibilizados os efeitos contextuais, o que resulta na alteração da avaliação da relevância.

A partir da análise de quatro dos principais fenômenos descritos por Sperber e Wilson (1995), na teoria da relevância, a saber, a formação do contexto, a suposição de relevância ótima, a irrelevância de informações e as condições para relevância, constatouse que, embora o princípio da relevância permaneça, seu comportamento sofre consideráveis alterações. Tais alterações, geralmente, tornam mais difícil atingir a relevância, uma vez que o esforço mental exigido ganha peso extra com a hipertextualidade e a bricolagem de diversas mídias.

O ambiente físico, uma das fontes das informações contextuais, não é o mesmo para os internautas que se comunicam, mas entra no processo. Por sua vez, o ambiente na web, que também entra como fonte de informações contextuais, envolve os dois comunicadores. A partir desses dois ambientes, cada interlocutor escolhe os enunciados mais relevantes para obter o máximo de efeitos contextuais, porém, as escolhas são diferenciadas devido às características do contexto, que inclui tanto o ambiente físico, quanto o virtual. Dessa forma, além das escolhas, também o recebimento das informações é alterado, gerando-se esforço mental extra para seu processamento.

Finalmente, a utilização, no chat, de sinais e marcas que não pertencem à escrita comum, para compensar a falta dos gestos e das expressões faciais, além do tom de voz, é forte indício para se considerar que os efeitos contextuais sejam disponibilizados e processados com a exigência de maior esforço para se atingir a relevância.

\section{Referências Bibliográficas}

ARAÚJO, J.C.R. A conversa na web: o estudo da transmutação em um gênero textual. In: MARCUSCHI, L.A, XAVIER, A.C. (org.), Hipertexto e gêneros digitais. Rio de Janeiro: Lucerna, 2004. p.91-109. 
ARAÚJO, J.C.R. Transmutação de gêneros na web: a emergência do chat. In: MARCUSCHI, L.A, XAVIER, A.C. (org.) Hipertexto e gêneros digitais: novas formas de construção de sentido. 3 ed. São Paulo: Contexto, 2010. 240 p.

BAKHTIN, M.M. Estética da criação verbal. 2. ed. São Paulo: Martins Fontes, 1997. $512 \mathrm{p}$.

MARCUSCHI, L.A, XAVIER, A.C. (org.) Hipertexto e gêneros digitais. Rio de Janeiro: Lucerna, 2004. 195 p.

MARCUSCHI, L.A, XAVIER, A.C. (org.) Hipertexto e gêneros digitais: novas formas de construção de sentido. 3 ed. São Paulo: Contexto, 2010. 240 p.

MARCUSCHI, L.A. Gêneros textuais emergentes no contexto da tecnologia digital. In: MARCUSCHI, L.A, XAVIER, A.C. (org.), Hipertexto e gêneros digitais: novas formas de construção de sentido. 3 ed. São Paulo: Contexto 2010. p. 15-80.

RAUEN F. J. Interação discente/docente em espaço virtual de aprendizagem: análise com base na teoria da relevância. Cadernos de Letras da UFF, v. 41, p. 231-250, 2010.

SPERBER, D. e WILSON, D. Relevance: communication and cognition. Oxford: Blackwell, 1986/1995. 326 p.

XAVIER, A.C.O. O hipertexto na sociedade da informação: a constituição do modo de enunciação digital. 2002. Tese de doutorado. Unicap.Campinas, 2002.

YUS, F. Alterations of relevance in cyber-media. Universitas Psychologica, n.3, pp. 629642, set.-dez. 2008.

WALLACE, P. The psychology of the internet. Cambridge: Cambridge University Press, 2001. 294 p.

Artigo recebido em: 26.02.2015

Artigo aprovado em: 29.06.2015 